\title{
Experimental investigation of ion-ion recombination under atmospheric conditions
}

\author{
A. Franchin ${ }^{1}$, S. Ehrhart ${ }^{2,10}$, J. Leppä ${ }^{3,4}$, T. Nieminen ${ }^{1,5}$, S. Gagné ${ }^{6,7}$, S. Schobesberger $^{1}$, D. Wimmer ${ }^{1}$, J. Duplissy ${ }^{5}$, \\ F. Riccobono ${ }^{8}$, E. M. Dunne ${ }^{9}$, L. Rondo ${ }^{10}$, A. Downard ${ }^{4}$, F. Bianchi ${ }^{8,11}$, A. Kupc ${ }^{12}$, G. Tsagkogeorgas ${ }^{13}$, K. Lehtipalo ${ }^{1}$, \\ H. E. Manninen ${ }^{1}$, J. Almeida ${ }^{2}$, A. Amorim ${ }^{14}$, P. E. Wagner $^{12}$, A. Hansel ${ }^{15}$, J. Kirkby ${ }^{2,10}$, A. Kürten ${ }^{10}$, \\ N. M. Donahue ${ }^{16}$, V. Makhmutov ${ }^{17}$, S. Mathot ${ }^{2}$, A. Metzger $^{15}$, T. Petäjä ${ }^{1}$, R. Schnitzhofer ${ }^{15}$, M. Sipilä ${ }^{1}$, Y. Stozhkov ${ }^{17}$,

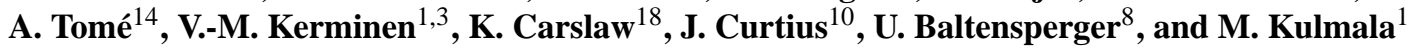 \\ ${ }^{1}$ Department of Physics, P.O. Box 64, 00014 University of Helsinki, Helsinki, Finland \\ ${ }^{2}$ CERN, 1211 Geneva, Switzerland \\ ${ }^{3}$ Finnish Meteorological Institute, Atmospheric Composition Research, P.O. Box 503, 00101 Helsinki, Finland \\ ${ }^{4}$ California Institute of Technology, Department of Chemical Engineering, 1200 E. California Blvd., Mail Code 101-20, \\ Pasadena, CA 91125, US \\ ${ }^{5}$ Helsinki Institute of Physics, Helsinki, Finland \\ ${ }^{6}$ Department of Physics and Atmospheric Science, Dalhousie University, Halifax, B3H 3J5, Canada \\ ${ }^{7}$ Environment Canada, Downsview, Toronto, M3H 5T4, Canada \\ ${ }^{8}$ Laboratory of Atmospheric Chemistry, Paul Scherrer Institute, 5232 Villigen, Switzerland \\ ${ }^{9}$ Finnish Meteorological Institute, Kuopio Unit, P.O. Box 1627, 70211 Kuopio, Finland \\ ${ }^{10}$ Institute for Atmospheric and Environmental Sciences, Goethe University Frankfurt, Altenhöferallee 1, 60438 \\ Frankfurt am Main, Germany \\ ${ }^{11}$ Institute for Atmospheric and Climate Science, ETH Zurich, 8092 Zurich, Switzerland \\ ${ }^{12}$ University of Vienna, Universitätsring 1, 1010 Vienna, Austria \\ ${ }^{13}$ Leibniz Institute for Tropospheric Research, Permoserstr. 15, 04318 Leipzig, Germany \\ ${ }^{14}$ CENTRA-SIM, F.C.U. Lisboa and U. Beira Interior, Portugal \\ ${ }^{15}$ Ionicon Analytik GmbH and University of Innsbruck, Institute for Ion and Applied Physics, 6020 Innsbruck, Austria \\ ${ }^{16}$ Carnegie Mellon University, Center for Atmospheric Particle Studies, 5000 Forbes Avenue, Pittsburgh, PA 15213, USA \\ ${ }^{17}$ Lebedev Physical Institute, Leninsky Prospect 53, 119991 Moscow, Russia \\ ${ }^{18}$ School of Earth and Environment, University of Leeds, LS2 9JT, Leeds, UK \\ Correspondence to: A. Franchin (alessandro.franchin@helsinki.fi)
}

Received: 01 December 2014 - Published in Atmos. Chem. Phys. Discuss.: 09 February 2015

Revised: 18 May 2015 - Accepted: 26 May 2015 - Published: 01 July 2015

\begin{abstract}
We present the results of laboratory measurements of the ion-ion recombination coefficient at different temperatures, relative humidities and concentrations of ozone and sulfur dioxide. The experiments were carried out using the Cosmics Leaving OUtdoor Droplets (CLOUD) chamber at CERN, the walls of which are made of conductive material, making it possible to measure small ions. We produced ions in the chamber using a $3.5 \mathrm{GeV} \mathrm{c}^{-1}$ beam of positively charged pions $\left(\pi^{+}\right)$generated by the CERN Proton Synchrotron (PS). When the PS was switched off, galactic
\end{abstract}

cosmic rays were the only ionization source in the chamber. The range of the ion production rate varied from 2 to $100 \mathrm{~cm}^{-3} \mathrm{~s}^{-1}$, covering the typical range of ionization throughout the troposphere. The temperature ranged from -55 to $20^{\circ} \mathrm{C}$, the relative humidity (RH) from 0 to $70 \%$, the $\mathrm{SO}_{2}$ concentration from 0 to $40 \mathrm{ppb}$, and the ozone concentration from 200 to $700 \mathrm{ppb}$. The best agreement of the retrieved ion-ion recombination coefficient with the commonly used literature value of $1.6 \times 10^{-6} \mathrm{~cm}^{3} \mathrm{~s}^{-1}$ was found at a temperature of $5{ }^{\circ} \mathrm{C}$ and a $\mathrm{RH}$ of $40 \%(1.5 \pm 0.6)$ 
$\times 10^{-6} \mathrm{~cm}^{3} \mathrm{~s}^{-1}$. At $20^{\circ} \mathrm{C}$ and $40 \% \mathrm{RH}$, the retrieved ion-ion recombination coefficient was instead $(2.3 \pm 0.7)$ $\times 10^{-6} \mathrm{~cm}^{3} \mathrm{~s}^{-1}$. We observed no dependency of the ion-ion recombination coefficient on ozone concentration and a weak variation with sulfur dioxide concentration. However, we observed a more than fourfold increase in the ion-ion recombination coefficient with decreasing temperature. We compared our results with three different models and found an overall agreement for temperatures above $0{ }^{\circ} \mathrm{C}$, but a disagreement at lower temperatures. We observed a strong increase in the recombination coefficient for decreasing relative humidities, which has not been reported previously.

\section{Introduction}

Air ions are fundamental to atmospheric electricity and play a central role in the proposed connection between solar activity, galactic cosmic rays (GCRs) and climate (Israël, 1970; Carslaw et al., 2002; Usoskin and Kovaltsov, 2008). Ions are known to enhance nucleation rates in atmospherically relevant vapor mixtures (Kirkby et al., 2011). In particular, ion-ion recombination has been proposed and studied as the driving force behind atmospheric nucleation (Yu and Turco, 2008; Yu, 2010; Nagato and Nakauchi, 2014). However, the overall effect of ions on atmospheric new particle formation (NPF), and subsequent production of cloud condensation nuclei, has remained a controversial issue (Gagné et al., 2008; Kazil et al., 2010; Manninen et al., 2010; Yu et al., 2010; Hirsikko et al., 2011; Kontkanen et al., 2013; Kulmala et al., 2013). Air ions accumulating near cloud edges may affect cloud microphysics and ultimately climate via several mechanisms that are currently poorly quantified (Tinsley, 2000; Harrison and Ambaum, 2008).

Atmospheric ions are usually classified into three groups depending on their diameter (here, all diameters are reported as Millikan-Fuchs equivalent mobility diameters, Mäkelä et al., 1996): small ions $(<1.9 \mathrm{~nm})$, intermediate ions (1.9$7.7 \mathrm{~nm})$ and large ions $(>7.7 \mathrm{~nm})$. In terms of mobility, they are classified as small ions $\left(>0.57 \mathrm{~cm}^{2} \mathrm{~V}^{-1} \mathrm{~s}^{-1}\right)$, intermediate ions $\left(4.3 \times 10^{-2}-0.57 \mathrm{~cm}^{2} \mathrm{~V}^{-1} \mathrm{~s}^{-1}\right)$ and large ions $\left(<4.3 \times 10^{-2} \mathrm{~cm}^{2} \mathrm{~V}^{-1}\right)$ (Hõrrak et al., 2000). Small ions have a high mobility; therefore, they are the main ones responsible for the transfer of charge in the atmosphere (Chalmers, 1949; Ogawa, 1985) and play a role in NPF and in aerosol charging processes (Adachi and Kousaka, 1985; Manninen et al., 2011). This work focuses on small ions, from here on simply referred to as "ions" unless specified otherwise.

Air ions are continuously produced in the atmosphere from GCRs and terrestrial sources, such as radon decay and gamma radiation from the soil (Laakso et al., 2004). Within the planetary boundary layer, terrestrial sources play an important role in ionization processes, whereas at alti-

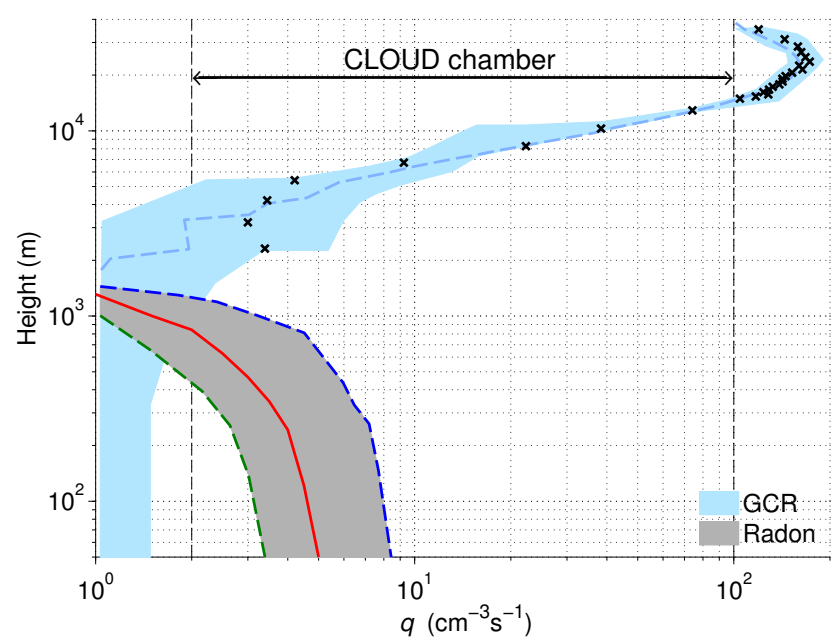

Figure 1. A vertical profile of the ion production rate $q$ based on literature data. The contribution of radon decay at mid-latitudes is shown in grey, accounting for seasonal variation. The minimum is in summer and the maximum is in winter (Zhang et al., 2011). The contribution of galactic cosmic rays at mid-latitudes, as presented by Usoskin et al. (2004), is shown in cyan. Black crosses indicate measurements by Harrison et al. (2014). The double arrow at the top shows the range of $q$ explored in this study.

tudes greater than $2 \mathrm{~km}$, GCRs are the dominant source of ions (Fig. 1; Harrison and Carslaw, 2003; Kazil and Lovejoy, 2004; Usoskin et al., 2004; Arnold, 2008; Zhang et al., 2011; Williams et al., 2011; Harrison et al., 2014).

When ionizing radiation hits an air molecule, an ionelectron pair is formed. The primary positive ion can be a molecular ion (e.g., $\mathrm{N}_{2}^{+}, \mathrm{O}_{2}^{+}$), but it can also be $\mathrm{N}^{+}$or $\mathrm{O}^{+}$, as the ionizing radiation is very energetic (Smith and Spanel, 1995; Volland, 1995; Leblanc et al., 2008). After the interaction between an air molecule and ionizing radiation, the newly formed positive ion stays in Brownian motion around its initial position. Its diffusion coefficient is similar to the one of the surrounding molecules and its change in momentum is negligible.

The electron, however, gains a finite momentum in the interaction. If the energy gained is sufficiently high, the electron starts to interact with atmospheric molecules, exciting and ionizing them, until its energy decreases to thermal levels and it binds to an electronegative molecule (for example, an electron and an $\mathrm{O}_{2}$ molecule, combining to form $\mathrm{O}_{2}^{-}$). This process takes place in a few nanoseconds.

Once molecular ions of opposite polarity are created, they can interact with molecules that have higher electronegativity or proton affinity (e.g., $\mathrm{H}_{2} \mathrm{O}$ ) and transfer their charge. Alternatively, they can establish hydrogen or other chemical bonds with other molecules and cluster (Smith and Spanel, 1995). Positive ions are transformed into hydronium-water clusters and ammonium-water clusters, reaching their equilibrium concentrations after about $10 \mu$ s (Luts and Salm, 1994; Luts, 


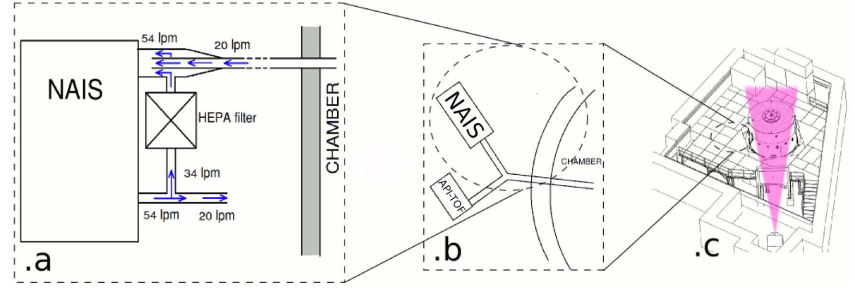

Figure 2. (a) Neutral cluster and Air Ion Spectrometer (NAIS) and its dilution system used during the CLOUD experiments. The sample air flow is withdrawn from the chamber at a flow rate that varies between 20 and $30 \mathrm{~L} \mathrm{~min}^{-1}$; sample air from the chamber is diluted with a portion of the exhaust air of the instrument, which is filtered with a High Efficiency Particulate Air (HEPA) filter and mixed with the sample air. (b) Configuration of the NAIS during the CLOUD experiments. (c) Sketch of the chamber and the beam. The dashed circle represents the area where the NAIS was located, outside of the beam trajectory. The beam is deliberately defocused to maximize the volume in the chamber where ionization takes place.

1998). After $1 \mathrm{~s}$, less abundant trace gases (such as pyridine and dimethylamine) start to be part of the clusters.

Negative primary ions (mainly $\mathrm{O}_{2}^{-}$) cluster with water molecules in $0.1 \mu \mathrm{s}$ and reach their equilibrium around $0.1 \mathrm{~s}$ after the interaction between air and ionizing radiation. Once at equilibrium, reactions with $\mathrm{NO}, \mathrm{NO}_{2}$ and $\mathrm{O}_{3}$ start to create nitric acid-water clusters. If present, iodine is known to cluster on longer timescales (several seconds) (Luts and Salm, 1994; Luts et al., 2011).

The number concentration of ions depends on the balance between ion sources and sinks. The production rate is proportional to the amount of ionizing radiation present, whereas the loss mechanisms depend on the attachment rate of ions onto aerosol or macroscopic surfaces and on the ion-ion recombination rate (Tammet et al., 2006). The ion-ion recombination rate is the rate at which one ion collides with another ion of opposite charge and gets neutralized. It depends on the mobility of ions and possibly on their chemical composition and ambient conditions.

Ion-ion recombination becomes dominant in extremely clean environments, where the integral of the aerosol surface distribution is negligible with respect to the ion-ion recombination rate, and the probability of ion-aerosol attachment is low (Volland, 1995). The attachment coefficient for an ion attaching to a neutral aerosol particle ranges from 0.1 to $2.0 \times 10^{-6} \mathrm{~cm}^{3} \mathrm{~s}^{-1}$, for an ion of $1.1 \mathrm{~nm}$ and an aerosol particle ranging from 10 to $100 \mathrm{~nm}$ mobility equivalent diameter (Tammet and Kulmala, 2005).

Recombination is also important at high ionization rates, when the production of ion pairs is so high that the probability of colliding with an aerosol particle is minimal with respect to the probability of colliding with an ion of opposite charge.

In the past, Bates and Flannery (1969) defined the equations to describe ion-ion recombination as a sink for air ions, continuing the theoretical work initiated by Thomson (1924) and continued by Natanson (1960). Hoppel and Frick (1986) studied the theory of ion-aerosol attachment, and its limiting case, ion-ion recombination, with the aim of enabling the use of differential mobility analysis to measure the aerosol population. McGowan (1965) studied ion-ion recombination in laboratory air to improve dosimetry techniques for ion chambers. Gringel et al. (1978) measured vertical profiles of air conductivity and showed good agreement up to $20 \mathrm{~km}$ altitude, using a theoretical recombination coefficient of small ions based on a three-body recombination process. Lee and Johnsen (1989) investigated ion-ion recombination in helium and argon at atmospheric densities and found that, in their setup, along with three-body recombination, stabilization by mutual neutralization played an important role. Heptner et al. (2012) conducted experiments to study relative changes in ion-ion recombination in dry filtered air at atmospheric pressure. In most of these cases, the ions were studied under conditions that were either far from those found in the atmosphere, or allowed little control over trace gas concentrations and ion production rates. In this work, we present the results of laboratory experiments performed under conditions close to those found in the Earth's atmosphere, providing quantitative results about the ion-ion recombination coefficient at varying temperature, relative humidity and trace gas concentrations.

\section{Experimental methods}

The typical experiment carried out consisted of measuring the ion concentrations at several beam intensities, each time for long enough (about $30 \mathrm{~min}$ ) to reach steady-state conditions while all the other variables were kept constant (Fig. 3). The ion concentrations were averaged over the last 10 $15 \mathrm{~min}$, before changing the beam intensity. The averaging time allowed us to compensate for occasional fluctuations in the ion concentrations that were caused by beam pulses, or by convective transport due to the two fans stirring the air inside the chamber. The beam intensity was varied from 0 to $1.5 \times 10^{5}$ pions s $^{-1}$, corresponding to an ion production rate ranging from about 2 to 100 ion pairs $\mathrm{cm}^{-3} \mathrm{~s}^{-1}$. The concentration of aerosol particles was constantly monitored with a CPC (TSI 3776) and it remained below $30 \mathrm{~cm}^{-3}$ in all experiments. The concentration of ions with $D_{\mathrm{p}}>1.9 \mathrm{~nm}$ was negligible as the experiments were carried out in an aerosolfree chamber. Usually, the beam intensity was increased consecutively, generating a series of steps of ion production rate. Each time, at the end of the last step, the beam shutter was closed, and we observed the ion concentration decay (Fig. 4). The mobility range of the ions considered in this study was from 3.2 to $0.57 \mathrm{~cm}^{2} \mathrm{~V}^{-1} \mathrm{~s}^{-1}$, which corresponds to a size range of $0.8-1.9 \mathrm{~nm}$ in mobility equivalent diameter $\left(D_{\mathrm{p}}\right)$. In this analysis, the signal of the NAIS in ion mode was integrated over all the channels corresponding to $D_{\mathrm{p}}<1.9 \mathrm{~nm}$. 


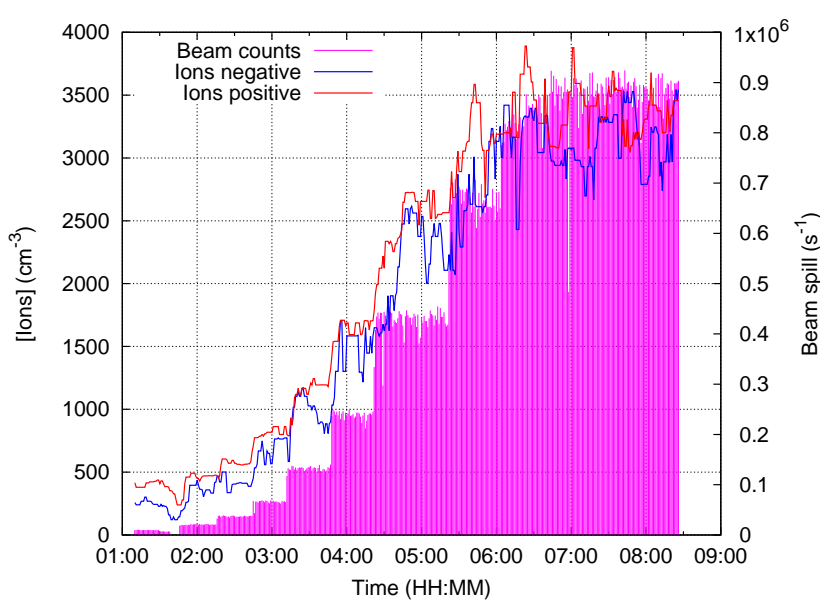

Figure 3. In a typical experiment, the beam intensity is varied, changing the flux of pions crossing the chamber. The beam intensity is directly proportional to the ion production rate (IPR) and is kept constant for a period of approximately $30 \mathrm{~min}$ at each step, to make sure that the ion concentration reaches the steady state. The mean ion concentration is related to the mean IPR at steady state via the balance equation (Eq. 1). Blue and red colors correspond to negative and positive ions, respectively. Magenta is the beam intensity.

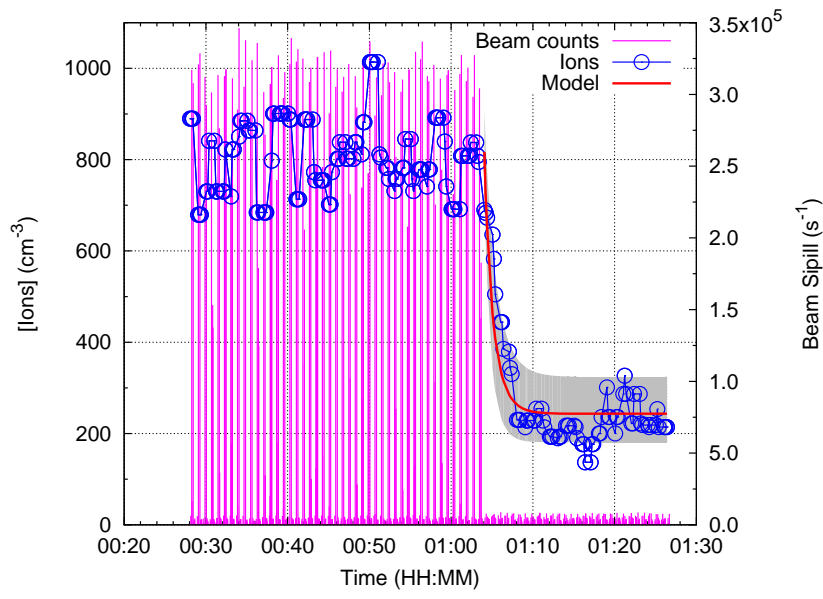

Figure 4. Typical ion decay experiment. The ion concentration (blue line and circles), the solution to Eq. (1) (red line) and the beam counts (magenta line). The ion concentration is presented as the average between the concentration of negative and positive ions. When solving Eq. (1), the recombination coefficient and linear loss term, retrieved independently by fitting the steady-state balance equation under the same conditions $(T=293 \mathrm{~K}, \mathrm{RH}=0 \%)$, were $9.3 \times 10^{-6} \mathrm{~cm}^{3} \mathrm{~s}^{-1}$ and $8.3 \times 10^{-3} \mathrm{~s}^{-1}$, respectively, and the ion production rate was $8.3 \mathrm{~cm}^{-3} \mathrm{~s}^{-1}$. The initial concentration of small ions, $n_{0}(t=01: 03)$, was $810 \mathrm{~cm}^{-3}$ (average over time range from 00:24 to 01:03 UTC). The grey shaded area is the model uncertainty assuming uncertainty of $\pm 30 \%$ on $n_{0}, \alpha$ and $\beta$.

The rest of the ion number size distribution was not considered, as it was negligible. From this data set, we retrieved the ion-ion recombination coefficient under different conditions.

\subsection{The CLOUD chamber}

The Cosmics Leaving OUtdoor Droplets (CLOUD) chamber (Kirkby et al., 2011) is a cylindrical vessel with a diameter of $3 \mathrm{~m}$ and a volume of $26.1 \mathrm{~m}^{3}$ made of electropolished $316 \mathrm{~L}$ stainless steel (Fig. 2c). Its walls are conductive, which makes it possible to measure small ions that, in a traditional aerosol chamber made of polytetrafluoroethylene (PTFE), would be removed in less than $1 \mathrm{~s}$ by the parasitic electric fields created by the dielectric material (McMurry and Rader, 1985). In the interior of the chamber, all plastic components are avoided using copper o-rings and metallic coating on electrically insulating components. When it is necessary to work in an ion-free environment, two circular grids, one located at the top and one at the bottom of the chamber, are provided with a potential difference of up to $60 \mathrm{kV}$, generating an axial electric field able to remove the small ions in less than $0.2 \mathrm{~s}$. When the two circular grids are not in use, they are grounded to avoid ground loops or parasitic electric fields.

The total in-flow to the chamber varies between 100 and $150 \mathrm{~L} \mathrm{~min}^{-1}$. Most of the flow is taken by the instruments connected to the chamber and a portion of it is purged through a valve that controls the pressure inside the chamber. The chamber is kept at 5 mbar above the atmospheric pressure to avoid contamination from the outside. The chamber is equipped with an ultraviolet fiber-optic system that is installed at the top plate of the chamber, allowing $\mathrm{OH}$ production (Kupc et al., 2011) without heating up the chamber. The temperature is controlled by air circulating between the chamber and the insulation surrounding it. The temperature ranges from -80 to $100^{\circ} \mathrm{C}$ with a stability inside the chamber of $\pm 0.1^{\circ} \mathrm{C}$ for each experiment. The chamber is filled with ultra-pure synthetic air, consisting of $\mathrm{N}_{2}$ and $\mathrm{O}_{2}$, obtained from the evaporation of liquid samples. The air is humidified with a Nafion system, using water purified by recirculation through Millipore Super-Q filters and irradiated with UV radiation. Ozone is produced by illuminating a portion of the incoming dry air with UV light. The other trace gases, such as $\mathrm{SO}_{2}$ and $\mathrm{NH}_{3}$, are added from gas cylinder reservoirs. These measures aim for the cleanest possible laboratory conditions (Schnitzhofer et al., 2014).

\subsection{The particle beam}

The particle beam is produced at the CERN Proton Synchrotron. The CLOUD chamber can be exposed to a $3.5 \mathrm{GeV} \mathrm{c}^{-1}$ positively charged pion $\left(\pi^{+}\right)$beam produced by a secondary target of aluminum or copper (Duplissy et al., 2010). The intensity of the particle beam can be varied to cover the full range of ionization in the troposphere, from an ion production rate of about $2 \mathrm{~cm}^{-3} \mathrm{~s}^{-1}$, equivalent to boundary layer levels, to $80 \mathrm{~cm}^{-3} \mathrm{~s}^{-1}$, equivalent to the levels in the free troposphere (Kazil and Lovejoy, 2004; Zhang et al., 2011). The beam consists of pions and muons that have ap- 
proximately the same energy of about $3.5 \mathrm{GeV}$ and come in spills. Each spill lasts for a few microseconds and delivers $10^{8}$ pions at a time, at intervals of $20 \mathrm{~s}$.

We varied the beam intensity, and thus the ion production rate in the chamber, by varying the aperture of the beam collimator, which consists of two mechanical jaws made of concrete that can slide vertically and horizontally. At full aperture $(60 \mathrm{~mm} \times 60 \mathrm{~mm})$, we have the maximum flux of pions through the chamber. When the collimator was partially closed, we reduced the flux of pions and we illuminated a smaller part of the chamber. When the collimator was closed, almost no pion could reach the chamber. In this case, only GCRs that pass through the chamber vertically, and some residual pions that pass the blocker, hitting the chamber horizontally, were responsible for the ionization. For this reason, the ion production rate in the chamber under GCR conditions was about $30 \%$ higher than it would be if the accelerator had been shut down completely.

The pion beam is deliberately defocused to maximize the area where the ionization takes place (Fig. 2c, shaded area). About $70 \%$ of the volume of the chamber is directly ionized and the two mixing fans produce a uniform distribution of ions inside the chamber; the mixing time inside the chamber is estimated to be between 1.7 and $3.6 \mathrm{~min}$ (Voigtländer et al., 2012).

\subsection{The hodoscope and the B1.2 counter}

The hodoscope is an array of scintillation detectors. It measures the pion flux through the chamber and gives accurate positional information on the particle beam. It consists of nine plastic scintillator slabs adjacent to one another in a vertical orientation and nine plastic scintillator slabs oriented horizontally (Mizin et al., 2011). The vertical and horizontal slabs form a grid orthogonal to the particle beam, covering an area of about $2 \mathrm{~m} \times 2 \mathrm{~m}$. An ionizing particle, hitting a point on this grid, is located by measuring the coincidence of the signal of two detectors (one vertical and one horizontal). The B1.2 counter consists of two scintillation detectors placed right in front of the beam aperture. It also measures the coincidence of the signal of two detectors in order to count only the pions from the beam. From the number of particles measured per unit time and from the location of the scintillators crossed, we can independently retrieve the beam intensity $(\mathrm{Hz})$ and its horizontal and vertical profile. This allows us to discriminate between high-energy particles coming from the beam, which travel almost horizontally, and the GCRs.

\subsection{Neutral cluster and Air Ion Spectrometer (NAIS)}

The Neutral cluster and Air Ion Spectrometer (NAIS, Gagné et al., 2011; Mirme and Mirme, 2013, SER NAIS12) is manufactured by Airel Ltd in Estonia and measures atmospheric ions in the range [0.8-42] nm and total aerosol particle pop- ulation in the range [2.5-42] nm. It consists of two cylindrical differential mobility analyzers (DMAs) working in parallel, classifying negative and positive ions at the same time (Manninen et al., 2009). The ions are simultaneously classified according to their mobility and detected by a stack of 21 electrometer rings for each analyzer. The device is equipped with a unipolar charging unit for each analyzer that can be switched on and off.

During the CLOUD experiments, the instrument operated in three modes: particle, ion and offset. In particle mode the main charging unit is turned on. In ion mode the main charging unit is turned off. In offset mode the main charger unit stays off and a filter unit is turned on to make a zero measurement. This zero measurement is used to determine the net signal due to ions and particles. To maximize the flow in the tube and reduce the diffusion losses, the NAIS and a mass spectrometer shared part of the $2.54 \mathrm{~cm}$ outer diameter sampling line. Outside the chamber, the flow was split (20 $\mathrm{L} \mathrm{min}^{-1}$ to the NAIS, $10 \mathrm{~L} \mathrm{~min}^{-1}$ to the APi-TOF) using a Y union (Fig. 2b).

The NAIS operates at a $54 \mathrm{Lmin}^{-1}$ total inlet flow. The high intake of the NAIS is a challenge in aerosol chamber experiments, where it is required to minimize the amount of air withdrawn. For this reason, the NAIS was operated with a recirculation system, which diluted the inlet flow with filtered air coming from the exhaust of the instrument. The filtered air formed an annulus around the sample flow (Fig. 2a). The use of the dilution system allowed us to reduce the withdrawn flow from the chamber from 54 to $20-30 \mathrm{~L} \mathrm{~min}^{-1}$. In this study, we only present the data recorded in ion mode, in particular the data from the first nine electrometers that collect ions with mobility diameter smaller than $1.9 \mathrm{~nm}$ (small ions). The detailed setup used for this work is presented in Fig. 2.

\section{Theoretical methods}

\subsection{Calculation of the ion-ion recombination rate}

Using the balance equation at steady state, the ion-ion recombination rate and a linear loss term were determined using the measured ion concentration and the ion production rate. We can describe the ionization processes inside the chamber using the following balance equation:

$\frac{\mathrm{d} n_{ \pm}}{\mathrm{d} t}=q-\alpha n_{+} n_{-}-\beta_{ \pm} n_{ \pm}-k_{\mathrm{CS}}\left(N, D_{\mathrm{p}}\right) n_{ \pm}$,

where $n_{ \pm}$is the absolute concentration of positive or negative small ions $\left(\mathrm{cm}^{-3}\right), q$ is the ion production rate (IPR, $\left.\mathrm{cm}^{-3} \mathrm{~s}^{-1}\right), \alpha$ is the recombination coefficient $\left(\mathrm{cm}^{3} \mathrm{~s}^{-1}\right), \beta$ is a first-order loss term $\left(\mathrm{s}^{-1}\right)$ that describes the ion-wall interactions in the aerosol chamber, and other loss mechanisms of the first order, and $k_{\mathrm{CS}}$ is the coagulation sink, i.e., the rate at which ions are lost by diffusion onto aerosol 


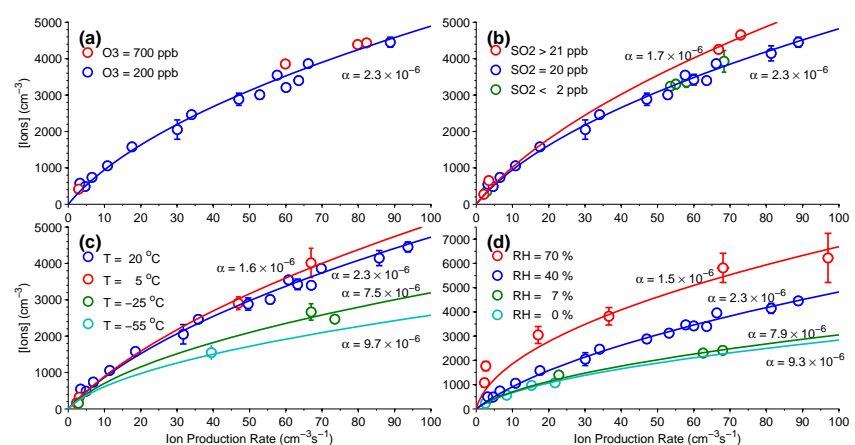

Figure 5. Ion concentration as a function of ion production rate at (a) two different ozone concentrations (at 200 and at $700 \mathrm{ppb}$ ); the other variables were kept constant $\left(T=20^{\circ} \mathrm{C}, \mathrm{RH}=40 \%\right.$ and $\left[\mathrm{SO}_{2}\right]=20 \mathrm{ppb}$ ); (b) different $\mathrm{SO}_{2}$ concentrations between 2 and $30 \mathrm{ppb}$; temperature, $\mathrm{RH}$ and ozone concentration were kept constant $\left(T=20^{\circ} \mathrm{C}, \mathrm{RH}=40 \%\right.$ and $\left.\left[\mathrm{SO}_{2}\right]=20 \mathrm{ppb}\right)$; (c) different temperatures $\left(20,5,-25\right.$ and $\left.-55^{\circ} \mathrm{C}\right)$; and (d) different relative humidities $(0,7,40$ and $70 \%)$ at a constant temperature of $20^{\circ} \mathrm{C}$. The ion concentration is presented as the average between the concentration of negative and positive ions, and the uncertainty is calculated as the standard deviation of the mean values at steady state.

particles $\left(\mathrm{s}^{-1}\right)$ (Kulmala et al., 2001; Leppä et al., 2011). At a constant $q$, the steady state that is eventually reached depends on the values of $\alpha, \beta$ and $k_{\mathrm{CS}}$.

In this study, $\alpha$ does not include the effect of initial recombination (Gryzinski et al., 2007). Initial recombination would mainly affect primary ions, which are not considered in our study that focuses on cluster ion-ion recombination, as the NAIS measures cluster ions with electrical mobility smaller than $3.2 \times 10^{-4} \mathrm{~m}^{2} \mathrm{~V}^{-1} \mathrm{~s}^{-1}$ (larger than $0.8 \mathrm{~nm}$ in mobility equivalent diameter).

We can make some assumptions to simplify Eq. (1). By assuming that $n_{-} \simeq n_{+}$, and that the ion loss by coagulation is negligible compared with the other sink terms, we get

$$
\frac{\mathrm{d} n}{\mathrm{~d} t}=q-\alpha n^{2}-\beta n,
$$

These assumptions were well posed in our case, since the average difference between the number concentration of positive and negative ions was $10 \%$. The 25 th and 75 th percentiles are 5 and $14 \%$, respectively (see Fig. 3). This variation in the concentration of positive and negative polarities is compatible with the ratio of the square root of the mean ion electrical mobilities $(Z)$, which is proportional to the loss rate of ions to the walls of the chamber $\sqrt{\frac{Z_{\mathrm{pos}}}{Z_{\mathrm{neg}}}}=0.9$. During our experiments, $k_{\mathrm{CS}}$ was constantly below $3 \times 10^{-7} s^{-1}$, due to negligible aerosol concentration in the chamber. The solution of Eq. (2) can be found analytically (Israël, 1970):

$$
n(t)=\frac{n_{1}\left(n_{0}-n_{2}\right)-n_{2}\left(n_{0}-n_{1}\right) \exp \left(-t \sqrt{\beta^{2}+4 \alpha q}\right)}{\left(n_{0}-n_{2}\right)-\left(n_{0}-n_{1}\right) \exp \left(-t \sqrt{\beta^{2}+4 \alpha q}\right)},
$$

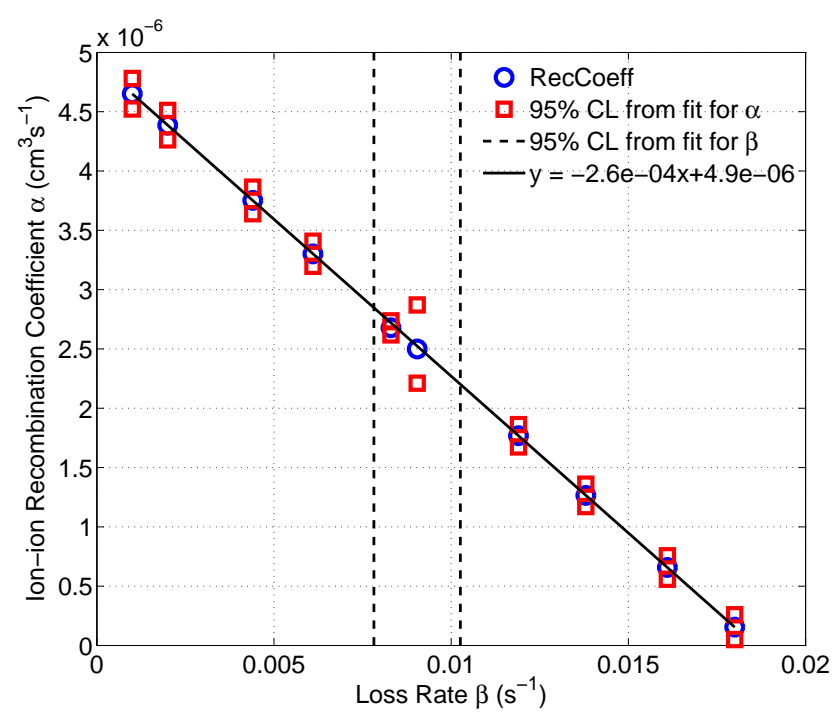

Figure 6. Variability of the retrieved recombination rate as a function of loss rate. The data set used here includes experiments performed at $\mathrm{T}=20^{\circ} \mathrm{C}$ and $\mathrm{RH}=40 \%$. The point at the center presents the larger confidence level interval as the loss term was kept as free parameter. The other points were obtained forcing the loss term $\beta$ to values varying from $1 \times 10^{-3}$ to $0.18 \mathrm{~s}^{-1}$.

where $n_{0}$ is the concentration of ions at $t=0, n_{1}=$ $\frac{-\beta+\sqrt{\beta^{2}+4 \alpha Q}}{2 \alpha}$ and $n_{2}=\frac{-\beta-\sqrt{\beta^{2}+4 \alpha Q}}{2 \alpha}$.

If we consider steady-state conditions, $\frac{\mathrm{d} n}{\mathrm{~d} t}=0$, Eq. (2) becomes a second-order polynomial. The recombination coefficient $\alpha$, and the linear loss term $\beta$, can be retrieved by fitting a second-order polynomial function to the data, treating them as free parameters. The ion concentration was set to 0 at $q$ equal to 0 . The linear loss term $\beta$, equal to $(8.3 \pm 1.6) \times 10^{-3} \mathrm{~s}^{-1}$, was calculated based on the data set with the best statistics $\left(T=20^{\circ} \mathrm{C}, \mathrm{RH}=38 \%\right)$. We assumed that the value of $\beta$ did not change in other cases. To check our assumption, we performed a sensitivity analysis of the ionion recombination coefficient $\alpha$, shown in Fig. 5. The variation in $\alpha$ for different assumed values of $\beta$ is linear and small compared with the observed variation of $\alpha$ due to changing conditions in the chamber.

Equation (3) was used to check the values of $\alpha$ and $\beta$ retrieved at steady state by comparing the resulting $n(t)$ to the ion decay data (Fig. 4). The ion production rate from the beam $\left(q_{\mathrm{b}}\right)$ was calculated using the following equation $(\mathrm{Du}-$ plissy et al., 2010):

$q_{\mathrm{b}}=N_{b} I L / V$,

where $N_{b}$ is the number of pions per unit time that hit the chamber. $N_{b}$ can vary between 0 and $1.5 \times 10^{6} \mathrm{~s}^{-1}$. $I=61$ i.p. $\mathrm{cm}^{-1}$ is the mean ionization per $\mathrm{cm}$ for a $3.5 \mathrm{GeV} / \mathrm{c} \pi^{+}$in air at s.t.p. (Smirnov, 2005), $L=284 \mathrm{~cm}$ is the path length of a beam particle in the chamber, and $V=26.1 \times 10^{6} \mathrm{~cm}^{3}$ is the chamber volume. The ion produc- 
tion rate was scaled for different air densities at different temperatures.

We used a value of $1.84 \mathrm{~cm}^{-3} \mathrm{~s}^{-1}$ for the intensity of the GCRs. The total ion production rate $q$ is given by the sum of the GCR contribution $q_{0}$ and the beam contribution $q_{\mathrm{b}}$, $q=q_{0}+q_{\mathrm{b}}$. The ion concentration was corrected for sample dilution, due to the dilution system described in Sect. 2.4 and shown in Fig. 2. The dilution system was tested in the laboratory and, for the flow range that was used in the experiments (20-25 $\mathrm{L} \mathrm{min}^{-1}$ ), it agreed within $28 \%$ with the ideal system used for our calculations.

\subsection{Modeled ion-ion recombination coefficient}

The temperature dependency of the calculated ion-ion recombination coefficient was compared to the values computed using three different model approaches. The first model derived by J. J. Thomson (Gardner, 1938; Loeb, 1955; Thomson and Thomson, 2013) considers recombination governed mainly by Brownian motion of ions and molecules and computes the recombination coefficient as

$\alpha=\sqrt{2} \pi d^{2} C \epsilon$

where $C=\sqrt{3 k_{b} T / m}$ is the root mean square thermal velocity of the ions, $d=e^{2} /\left[(3 / 2) k_{B} T\right]$ is the distance where the Coulomb potential energy between the two ions of opposite polarity is equal to their thermal kinetic energy, and $\epsilon$ is the probability of the two ions to recombine once they are at distance $d$. As derived by Thomson, $\epsilon=2 w-w^{2}$, $w=1-2[1-\exp (-x)(x+1)] / x^{2}, x=2 d / L$ and $L$ is the mean free path of the ions. The equation for $\alpha$ then becomes

$\alpha\left(\mathrm{cm}^{3} \mathrm{~s}^{-1}\right)=1.90 \times 10^{-5}(273 / T)^{\frac{3}{2}} 3 / 2 \sqrt{1 / M} \epsilon$,

when $T$ is the temperature in Kelvin and $M$ is the mass of the ion in Da.

The second model taken into consideration and compared with our experimental data is described by López-Yglesias and Flagan (2013). Based on Hoppel and Frick (1986), this model was developed for ion-aerosol attachment, but it can be used to compute the recombination coefficient, if we use an aerosol that is as small as the ion and with opposite charge. The model accounts for Brownian motion, Coulombic interaction, image charging, polarization of the molecules and three-body trapping.

The third model, by Brasseur and Chatel (1983), is a parametrization used for describing the ions in the stratosphere based on earlier work by Bates (1982) and Smith and Adams (1982) that has the expression

$\alpha\left(\mathrm{cm}^{3} \mathrm{~s}^{-1}\right)=6 \times 10^{-8} \sqrt{300 / T}+6 \times 10^{-26}\left[M_{\text {air }}\right](300 / T)^{4}$,

where $\left[M_{\text {air }}\right]$ is the concentration of air molecules in $\mathrm{cm}^{-3}$.

\section{Results and discussion}

The ion-ion recombination was measured in the CLOUD chamber at different temperatures, relative humidities and concentrations of ozone and sulfur dioxide. We obtained a value of $2.3 \pm 0.7 \times 10^{-6} \mathrm{~cm}^{3} \mathrm{~s}^{-1}$, at $298 \mathrm{~K}$ and $\mathrm{RH}=40 \%$, higher than the constant value of $1.6 \times 10^{-6} \mathrm{~cm}^{3} \mathrm{~s}^{-1}$ usually reported in the literature (Laakso et al., 2004). Interestingly, we found that $\alpha$ depends on both temperature and relative humidity (Tables A2 and A1). Figure 5 shows the results of four sets of experiments, where the ion concentration was measured as a function of $q$. For each set of experiments, we kept all the parameters constant except the one under investigation: the concentration of ozone (200-700 ppb), sulfur dioxide (0-50 ppb), temperature $(218,248,278$ and $293 \mathrm{~K})$ and relative humidity $(0,7,40$ and $70 \%)$. The measured recombination rate showed a strong dependency (about a factor of 5 change) on temperature and relative humidity and, to some extent (a factor of 2), on the concentration of sulfur dioxide. The variability in the ozone concentration appeared to have little influence, if any, on the measured recombination rate.

The retrieved loss rate for ions $\left(8.3 \times 10^{-3} \mathrm{~s}^{-1}\right.$, Fig. 6), differs markedly from the linear loss rate retrieved for the sulfuric acid neutral monomer $\left(1.7 \times 10^{-3} \mathrm{~s}^{-1}\right.$, Almeida et al., 2013). This difference between the loss rates might be partially explained by the image charge effect of the ions with the chamber walls, even though this remains a controversial topic (McMurry and Rader, 1985; Mayya and Sapra, 2002; Vauge, 2002; Chang et al., 2012). Losses might be due to some non-ideal behavior, e.g., retention of surface charge, of some insulator in the clearing field cage region or in proximity to the mixing fans. Yet another possibility is that the mixing in the chamber influences the ion concentrations, creating a higher linear loss rate. Finally, it is possible that sulfuric acid is not lost to the walls with unit efficiency.

\subsection{Temperature and relative humidity dependency of the recombination rate}

The strongest effect we observed was an increase in the ionion recombination coefficient with decreasing temperature (Fig. 5). The ion-ion recombination coefficient increased by approximately a factor of 4 (from 2.3 to $9.9 \times 10^{-6} \mathrm{~cm}^{3} \mathrm{~s}^{-1}$ ) as temperature decreased from 293 to $218 \mathrm{~K}$. This behavior seems not to be predicted by two of the three models and only partially by the third model, as shown in Fig. 8. Interestingly, all the models agree with each other and with the experimental results over a range of temperatures from 273 to $298 \mathrm{~K}$, but there are big discrepancies in the absolute values as well as in the functional form of the temperature dependency at temperatures below $273 \mathrm{~K}$. The model that seems to agree best with our data is the one by Brasseur and Chatel (1983), linked more directly to atmospheric data. The model by López-Yglesias and Flagan (2013) that accounts accu- 
rately for all the possible physical processes does not agree with our data. Another option could be related to the evaporation of ions in the line. If the number of ions reaching the instrument was lower because of the losses for evaporation, the resulting recombination would be overestimated. The effect of the mixing fan and the chemical composition of the ions could vary with temperature, which would affect the recombination coefficient.

We observed a strong dependency of the recombination coefficient on relative humidity (RH). The ion-ion recombination coefficient decreases with decreasing $\mathrm{RH}$ from $9.4 \times 10^{-6}$ to $2.0 \times 10^{-6} \mathrm{~cm}^{3} \mathrm{~s}^{-1}$ as RH drops from 70 to $0 \%$, at a constant temperature of $298 \mathrm{~K}$ (Fig. 7). The decrease of the ion-ion recombination coefficient at increasing $\mathrm{RH}$ values could be related to an increase in size of the small ions: higher values of $\mathrm{RH}$ would form larger hydrated ions that would be less mobile, thus decreasing the recombination rate. The change in ion mobility is plausible, as we know that aerosol particles with a diameter larger than $10 \mathrm{~nm}$ tend to be hygroscopic, changing their diameter according to the RH (Onasch et al., 1999; Keskinen et al., 2013). We also know, from quantum chemistry calculations, that ions form clusters with water and that the amount of water attached is dependent on RH (Kurtén et al., 2007; Husar et al., 2012; Henschel et al., 2014; Olenius et al., 2014). This explanation matches the observed data qualitatively. In fact, according to quantum calculations shown in Kurtén et al. (2007) for sulfuric acid ions at $20 \% \mathrm{RH}$, there are mostly one or two molecules of water in the cluster, whereas at $80 \% \mathrm{RH}$, there are three or four. We get the equation below if we assume that the ions in the chamber (1) are mainly sulfuric acid molecules, or behave the same way as sulfuric acid molecules, (2) are perfect spheres, and (3) that their mass is the sum of the masses of the molecules that comprise the ions.

$D_{\mathrm{p}}=\sqrt[3]{\frac{6 \cdot\left(M_{\mathrm{H}_{2} \mathrm{SO}_{4}}+M_{\mathrm{H}_{2} \mathrm{O}} \cdot n_{w}\right)}{\pi \rho}}+0.3 \mathrm{~nm}$,

with

$\rho=\rho\left(n_{w}\right)=\frac{M_{\mathrm{H}_{2} \mathrm{SO}_{4}} \cdot \rho_{\mathrm{H}_{2} \mathrm{SO}_{4}}+M_{\mathrm{H}_{2} \mathrm{O}} \cdot \rho_{\mathrm{H}_{2} \mathrm{O}} \cdot n_{w}}{M_{\mathrm{H}_{2} \mathrm{SO}_{4}}+n_{w} \cdot M_{\mathrm{H}_{2} \mathrm{SO}_{4}}}$

where $D_{\mathrm{p}}$ is the mobility diameter of the ions, $M_{\mathrm{H}_{2} \mathrm{SO}_{4}}$ and $M_{\mathrm{H}_{2} \mathrm{O}}$ are the masses in Da of a sulfuric acid molecule and of a water molecule, respectively, $n_{\mathrm{w}}$ is the number of water molecules in a cluster and $0.3 \mathrm{~nm}$ is the difference between mobility diameter and mass diameter (Mäkelä et al., 1996; $\mathrm{Ku}$ and de la Mora, 2009). This calculation gives a $D_{\mathrm{p}}$ of $0.91-0.94 \mathrm{~nm}$ at $20 \% \mathrm{RH}$ and of $0.94-1.01 \mathrm{~nm}$ at $80 \% \mathrm{RH}$. Unfortunately, the effect of $\mathrm{RH}$ on the ion diameter could not be observed directly, because this change in diameter is too small to be detected by the NAIS, given its low size resolution (Mirme and Mirme, 2013). However, the RH dependency of the recombination coefficient as a change in ion mobility is unclear, and cannot be predicted satisfactorily by

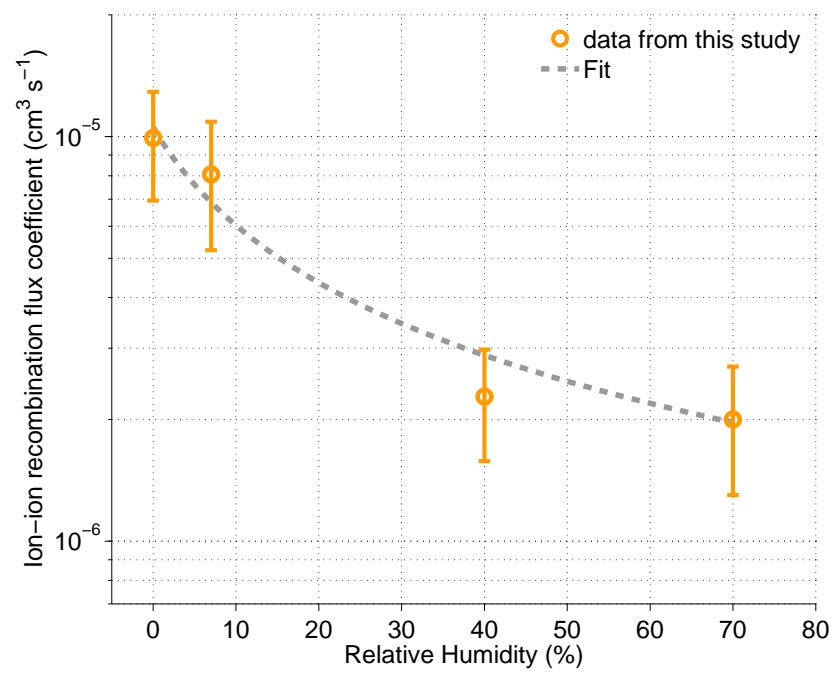

Figure 7. The ion-ion recombination coefficient measured at different relative humidities, at a constant temperature of $20^{\circ} \mathrm{C}$. The dots are measured points; the dashed line is an exponential fit to guide the eye.

any of the models found in the literature. Only the model described in Gardner (1938) predicts an increase of the recombination coefficient for smaller ions, although it underestimates the absolute values.

\subsection{Atmospheric implications}

It is important to account for the ion-ion recombination when modeling ion concentrations. As described by Eq. (1), the term representing the ion-ion recombination is always present and becomes dominant for large ion production rates and when coagulation sinks are small, e.g., in the free troposphere (Volland, 1995).

The possibility of a strong dependency of the ion-ion recombination rate on temperature must be taken into account when interpreting and modeling data of ion concentration or ion production in environments or model domains with a large temperature variability. In fact, a change in temperature from -54 to $20^{\circ} \mathrm{C}$, a typical temperature change from the free troposphere down to the boundary layer, can cause a change in the recombination rate as high as 1 order of magnitude.

The RH seems to influence the rate of recombination as well, by decreasing the mobility of ions. In this study, the measurements at different RHs were taken at constant temperature and, therefore, changes in $\mathrm{RH}$ reflect those in the absolute water vapor concentration. The lower the RH, the faster the ion loss via recombination was. This might be analogous to what happens at high altitudes, where water molecules are scarce.

It should be noted that, in the present study, the pressure was kept constant at +5 mbar above the atmospheric level, during the experiments. In the atmosphere, however, a de- 


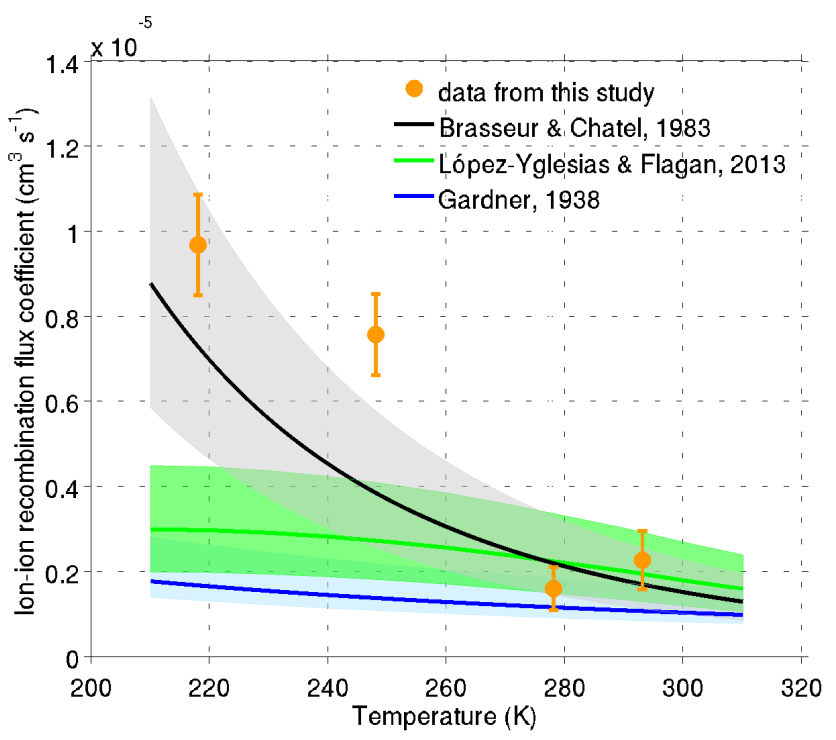

Figure 8. A comparison between the ion-ion recombination coefficient, measured at different temperatures (points with error bars) and the recombination coefficient modeled using different models. The shaded area represents $50 \%$ uncertainty.

crease in temperature with increasing altitude is associated with a decrease in pressure as well. In the CLOUD chamber it is not possible to lower the pressure below typical sea level values, as the chamber is not designed to withstand under-pressure with respect to the outside pressure. So, it was not possible to experimentally measure the variation of the ion-ion recombination rate at pressures lower than $900 \mathrm{hPa}$. It has been shown, however, that the ion-to-particle coefficients are considerably different under ambient conditions at $20 \mathrm{~km}$ altitude than at ground level, with the recombination coefficient being an order of magnitude lower at $20 \mathrm{~km}$ altitude than at ground level (López-Yglesias and Flagan, 2013). When moving from ground level to $20 \mathrm{~km}$ altitude, the decrease in recombination coefficient due to decrease in pressure is only partly counterbalanced by the increase in recombination coefficient due to decrease in temperature. Consequently, the pressure effect on a recombination coefficient needs to be taken into account when interpreting data measured at substantially different pressure than in this work, but investigating the pressure effect is beyond the scope of this study.

\section{Conclusions}

We carried out an experimental determination of the ionion recombination coefficient in the CLOUD chamber at CERN. The retrieved recombination coefficient at $20^{\circ} \mathrm{C}$ and $40 \%$ RH agrees with the literature values and with the models. We see no clear dependency of the ion-ion recombination rate coefficient for different ozone concentrations and only a weak variation at varying sulfur dioxide concentrations. Instead, we notice a strong dependency of the ionion recombination coefficient on temperature and relative humidity that has not been reported in previous studies. The ion-ion recombination coefficient varied between $9.7 \times 10^{-6}$ and $2.3 \times 10^{-6} \mathrm{~cm}^{3} \mathrm{~s}^{-1}$ over the temperature range 220 to $293 \mathrm{~K}$ and between $9.3 \times 10^{-6}$ and $1.5 \times 10^{-6} \mathrm{~cm}^{3} \mathrm{~s}^{-1}$ over the range of relative humidities from 0 to $70 \%$. The temperature dependency is not well described by any of the models found in the literature; only the model by Brasseur and Chatel (1983) seems to give results following the temperature dependence of our experimental data within $50 \%$ uncertainty. The RH dependency of the ion-ion recombination coefficient is not well understood or described theoretically, but can be interpreted as an effect of ion hydration: ions clustering with water molecules decreases their mobility, and therefore they recombine at a lower rate. Only the model by Gardner (1938) shows a functional dependency that supports this explanation, but it fails in reproducing the absolute values. It is also important to note that our results for the RH dependence of the ion-ion recombination coefficient were studied for only one temperature, $20^{\circ} \mathrm{C}$, and that the extent of the dependency might be different at different temperatures.

This was the first study to investigate experimentally the ion-ion recombination in a highly controlled environment at atmospherically relevant temperature, humidity and trace gas concentrations. Our main finding was that the recombination coefficient depends strongly on temperature and relative humidity, quantities that have a large variability in the troposphere. This work can be considered as a starting point for future studies in which pressure, chamber inhomogeneities and ion chemical composition could be taken into account. 
Appendix A: Solution of the balance equation

$\frac{\mathrm{d} n}{\mathrm{~d} t}=Q-\alpha n^{2}-\beta n$.

The right-hand term of Eq. (A1) is a second-degree equation; therefore,

$\frac{\mathrm{d} n}{\mathrm{~d} t}=-\alpha\left(n-n_{1}\right)\left(n-n_{2}\right)$,

where

$n_{1}=\frac{-\beta+\sqrt{\beta^{2}+4 \alpha Q}}{2 \alpha}$

and

$n_{2}=\frac{-\beta-\sqrt{\beta^{2}+4 \alpha Q}}{2 \alpha}$

are the solutions. Using the method of separation of variables, Eq. (A2) becomes

$\frac{\mathrm{d} n}{\left(n-n_{1}\right)\left(n-n_{2}\right)}=-\alpha \mathrm{d} t$.

Integrating, Eq. (A3) can be written as

$\int_{n_{0}}^{n}\left(\frac{A}{n-n_{1}}+\frac{B}{n-n_{2}}\right) \mathrm{d} n=\int_{0}^{t}-\alpha \mathrm{d} t$,

where $n_{0}$ is the ion concentration at $t=0$ and $A\left(n-n_{2}\right)+$ $B\left(n-n_{1}\right)=1 . A\left(n-n_{2}\right)+B\left(n-n_{1}\right)=1$ can be written as $n(A+B)-\left(A n_{2}+B n_{1}\right)=1$ and its solution is

$A=-B=\frac{1}{\left(n_{1}-n_{2}\right)}=\frac{\alpha}{\sqrt{\beta^{2}+4 \alpha Q}}$.

Table A1. Values of the recombination coefficient and its uncertainty at different temperatures. The uncertainty reported is calculated with error propagation and includes the uncertainty in the fit.

\begin{tabular}{ccc}
\hline $\begin{array}{c}T \\
\left({ }^{\circ} \mathrm{C}\right)\end{array}$ & $\begin{array}{c}\alpha \times 10^{-6} \\
\left(\mathrm{~cm}^{3} \mathrm{~s}^{-1}\right)\end{array}$ & $\begin{array}{c}\sigma_{\alpha} \times 10^{-6} \\
\left(\mathrm{~cm}^{3} \mathrm{~s}^{-1}\right)\end{array}$ \\
\hline 20 & 2.3 & 0.7 \\
5 & 1.6 & 0.6 \\
-25 & 7.6 & 1.0 \\
-55 & 9.7 & 1.2 \\
\hline
\end{tabular}

By solving Eq. (A4), we obtain

$A \ln \left(\frac{\left|n-n_{1}\right|}{\left|n_{0}-n_{1}\right|}\right)-A \ln \left(\frac{\left|n-n_{2}\right|}{\left|n_{0}-n_{2}\right|}\right)=-\alpha t$.

We can drop the absolute value because these values are always greater than 0 :

$A \ln \left(\frac{n-n_{1}}{n_{0}-n_{1}}\right)-A \ln \left(\frac{n-n_{2}}{n_{0}-n_{2}}\right)=-\alpha t$

$A \ln \left\{\frac{\left(n-n_{1}\right)\left(n_{0}-n_{2}\right)}{\left(n-n_{2}\right)\left(n_{0}-n_{1}\right)}\right\}=-\alpha t$

$\frac{\left(n-n_{1}\right)}{\left(n-n_{2}\right)}=\frac{\left(n_{0}-n_{1}\right)}{\left(n_{0}-n_{2}\right)} \exp \left(-\sqrt{\beta^{2}+4 \alpha Q t}\right)$

From this, we can solve $n(t)$ :

$n(t)=\frac{\left(n_{0}-n_{2}\right) n_{1}-n_{2}\left(n_{0}-n_{1}\right) \exp \left(-t \sqrt{\beta^{2}+4 \alpha Q}\right)}{\left(n_{0}-n_{2}\right)-\left(n_{0}-n_{1}\right) \exp \left(-t \sqrt{\beta^{2}+4 \alpha Q}\right)}$.

Table A2. Values of the recombination coefficient and its uncertainty at different relative humidities. The uncertainty reported is calculated with error propagation and includes the uncertainty in the fit.

\begin{tabular}{ccc}
\hline $\begin{array}{c}\mathrm{RH} \\
(\%)\end{array}$ & $\begin{array}{c}\alpha \times 10^{-6} \\
\left(\mathrm{~cm}^{3} \mathrm{~s}^{-1}\right)\end{array}$ & $\begin{array}{c}\sigma_{\alpha} \times 10^{-6} \\
\left(\mathrm{~cm}^{3} \mathrm{~s}^{-1}\right)\end{array}$ \\
\hline 70 & 2.0 & 0.7 \\
40 & 2.3 & 0.7 \\
7 & 8.1 & 2.8 \\
0 & 9.9 & 3.0 \\
\hline
\end{tabular}

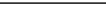


Acknowledgements. We would like to thank CERN for supporting CLOUD with important technical resources and for providing a particle beam from the CERN Proton Synchrotron. This research has received funding from the EC's Seventh Framework Program under grant agreement number 215072 (CLOUD-ITN Marie Curie Initial Training Network) and from the Academy of Finland, via the Center of Excellence program (project number 1118615). Thanks to the German Federal Ministry of Education and Research (project number 01LK0902A). J. Leppä would like to acknowledge the financial support from the Magnus Ehrnrooth Foundation, the Jane and Aatos Erkko Foundation and the Emil Aaltonen Foundation. This research has been supported by a Marie Curie Early Initial Training Network Fellowship of the European Community's Seventh Framework Program under contract number PITN-GA-2012-316662-CLOUD-TRAIN.

Edited by: J. H. Seinfeld

\section{References}

Adachi, M. and Kousaka, Y.: Unipolar and bipolar diffusion charging of ultrafine aerosol particles, J. Aerosol Sci., 16, 109-123, doi:10.1016/0021-8502(85)90079-5, 1985.

Almeida, J., Schobesberger, S., Kurten, A., Ortega, I. K., Kupiainen-Maatta, O., Praplan, A. P., Adamov, A., Amorim, A., Bianchi, F., Breitenlechner, M., David, A., Dommen, J., Donahue, N. M., Downard, A., Dunne, E., Duplissy, J., Ehrhart, S., Flagan, R. C., Franchin, A., Guida, R., Hakala, J., Hansel, A., Heinritzi, M., Henschel, H., Jokinen, T., Junninen, H., Kajos, M., Kangasluoma, J., Keskinen, H., Kupc, A., Kurten, T., Kvashin, A. N., Laaksonen, A., Lehtipalo, K., Leiminger, M., Leppä, J., Loukonen, V., Makhmutov, V., Mathot, S., McGrath, M. J., Nieminen, T., Olenius, T., Onnela, A., Petäjä, T., Riccobono, F., Riipinen, I., Rissanen, M., Rondo, L., Ruuskanen, T., Santos, F. D., Sarnela, N., Schallhart, S., Schnitzhofer, R., Seinfeld, J. H., Simon, M., Sipilä, M., Stozhkov, Y., Stratmann, F., Tome, A., Trostl, J., Tsagkogeorgas, G., Vaattovaara, P., Viisanen, Y., Virtanen, A., Vrtala, A., Wagner, P. E., Weingartner, E., Wex, H., Williamson, C., Wimmer, D., Ye, P., Yli-Juuti, T., Carslaw, K. S., Kulmala, M., Curtius, J., Baltensperger, U., Worsnop, D. R., Vehkämäki, H., and Kirkby, J.: Molecular understanding of sulphuric acid-amine particle nucleation in the atmosphere, Nature, 502, 359-363, doi:10.1038/nature12663, 2013.

Arnold, F.: Atmospheric Ions and Aerosol Formation, Space Sci. Rev., 137, 225-239, doi:10.1007/s11214-008-9390-8, 2008.

Bates, D. R.: Recombination of small ions in the troposphere and lower stratosphere, Planetary and Space Science, 30, 1275-1282, doi:10.1016/0032-0633(82)90101-5, 1982.

Bates, D. R. and Flannery, M. R.: Three-body ionic recombination at moderate and high gas densities, J. Phys. B-At. Mol. Opt., 2, 184-190, doi:10.1088/0022-3700/2/2/306, 1969.

Brasseur, G. and Chatel, A.: Modeling of stratospheric ions: A first attempt, Ann. Geophys., 1, 173-85, 1983, http://www.ann-geophys.net/1/173/1983/.

Carslaw, K. S., Harrison, R. G., and Kirkby, J.: Cosmic rays, clouds and climate, Science, 298, 1732-1737, 2002.

Chalmers, J. A.: Atmospheric electricity, Clarendon Press, Oxford, England, 1949.
Chang, K.-N., Chen, Y.-K., Huang, S.-H., Chen, C.-W., Lai, C.-Y., and Chen, C.-C.: Penetration of charged particles through metallic tubes, J. Aerosol Sci., 48, 10-17, doi:10.1016/j.jaerosci.2012.01.006, 2012.

Duplissy, J., Enghoff, M. B., Aplin, K. L., Arnold, F., Aufmhoff, H., Avngaard, M., Baltensperger, U., Bondo, T., Bingham, R., Carslaw, K., Curtius, J., David, A., Fastrup, B., Gagné, S., Hahn, F., Harrison, R. G., Kellett, B., Kirkby, J., Kulmala, M., Laakso, L., Laaksonen, A., Lillestol, E., Lockwood, M., Mäkelä, J., Makhmutov, V., Marsh, N. D., Nieminen, T., Onnela, A., Pedersen, E., Pedersen, J. O. P., Polny, J., Reichl, U., Seinfeld, J. H., Sipilä, M., Stozhkov, Y., Stratmann, F., Svensmark, H., Svensmark, J., Veenhof, R., Verheggen, B., Viisanen, Y., Wagner, P. E., Wehrle, G., Weingartner, E., Wex, H., Wilhelmsson, M., and Winkler, P. M.: Results from the CERN pilot CLOUD experiment, Atmos. Chem. Phys., 10, 1635-1647, doi:10.5194/acp-101635-2010, 2010.

Gagné, S., Laakso, L., Petäjä, T., Kerminen, V.-M., and Kulmala, M.: Analysis of one year of Ion-DMPS data from the SMEAR II station, Finland, Tellus B, 60, 318-319, 2008.

Gagné, S., Lehtipalo, K., Manninen, H. E., Nieminen, T., Schobesberger, S., Franchin, A., Yli-Juuti, T., Boulon, J., Sonntag, A., Mirme, S., Mirme, A., Hõrrak, U., Petäjä, T., Asmi, E., and Kulmala, M.: Intercomparison of air ion spectrometers: an evaluation of results in varying conditions, Atmos. Meas. Tech., 4, 805-822, doi:10.5194/amt-4-805-2011, 2011.

Gardner, M. E.: The Recombination of Ions in Pure Oxygen as a Function of Pressure and Temperature, Phys. Rev., 53, 75-83, doi:10.1103/PhysRev.53.75, 1938.

Gringel, W., Käselau, K. H., and Mühleisen, R.: Recombination rates of small ions and their attachment to aerosol particles, Pure Appl. Feophys., 116, 1101-1113, doi:10.1007/BF00874674, 1978.

Gryzinski, M. A., Golnik, N., and Zielczynski, M.: Initial recombination of ions in ionization chambers filled with hydrocarbon gases, Nukleonika, 52, 7-12, 2007.

Hõrrak, U., Salm, J., and Tammet, H.: Statistical characterization of air ion mobility spectra at Tahkuse Observatory: Classification of air ions, J. Geophys. Res., 105, 9291-9302, doi:10.1029/1999JD901197, 2000.

Harrison, R. G. and Ambaum, M. H. P.: Enhancement of cloud formation by droplet charging, Proc. R. Soc., 464, 2561-2573, 2008.

Harrison, R. G. and Carslaw, K. S.: Ion-aerosol-cloud processes in the lower atmosphere, Rev. Geophys., 41, 1012, doi:10.1029/2002RG000114, 2003.

Harrison, R. G., Nicoll, K. A., and Aplin, K. L.: Vertical profile measurements of lower troposphere ionisation, J. Atmos. Sol.Terr. Phy., 119, 203-210, doi:10.1016/j.jastp.2014.08.006, 2014.

Henschel, H., Navarro, J. C. A., Yli-Juuti, T., Kupiainen-Määttä, O., Olenius, T., Ortega, I. K., Clegg, S. L., Kurtén, T., Riipinen, I., and Vehkamäki, H.: Hydration of Atmospherically Relevant Molecular Clusters: Computational Chemistry and Classical Thermodynamics, J. Phys. Chem. A, 118, 2599-2611, doi:10.1021/jp500712y, 2014.

Heptner, A., Cochems, P., Langejuergen, J., Gunzer, F., and Zimmermann, S.: Investigation of ion-ion-recombination at atmospheric pressure with a pulsed electron gun, The Analyst, 137, 5105-5112, doi:10.1039/c2an35849b, 2012. 
Hirsikko, A., Nieminen, T., Gagné, S., Lehtipalo, K., Manninen, H. E., Ehn, M., Hõrrak, U., Kerminen, V.-M., Laakso, L., McMurry, P. H., Mirme, A., Mirme, S., Petäjä, T., Tammet, H., Vakkari, V., Vana, M., and Kulmala, M.: Atmospheric ions and nucleation: a review of observations, Atmos. Chem. Phys., 11, 767798, doi:10.5194/acp-11-767-2011, 2011.

Hoppel, W. A. and Frick, G. M.: Ion-Aerosol Attachment Coefficients and the Steady-State Charge Distribution on Aerosols in a Bipolar Ion Environment, Aerosol Sci. Tech., 5, 1-21, doi:10.1080/02786828608959073, 1986.

Husar, D. E., Temelso, B., Ashworth, A. L., and Shields, G. C.: Hydration of the Bisulfate Ion: Atmospheric Implications, J. Phys. Chem. A, 116, 5151-5163, doi:10.1021/jp300717j, 2012.

Israël, H.: Atmospheric Electricity: Fundamentals, conductivity, ions, Israel Program for Scientific Translations, Jerusalem, 1970.

Kazil, J. and Lovejoy, E. R.: Tropospheric ionization and aerosol production: A model study, J. Geophys. Res., 109, D19206, doi:10.1029/2004JD004852, 2004.

Kazil, J., Stier, P., Zhang, K., Quaas, J., Kinne, S., O’Donnell, D., Rast, S., Esch, M., Ferrachat, S., Lohmann, U., and Feichter, J.: Aerosol nucleation and its role for clouds and Earth's radiative forcing in the aerosol-climate model ECHAM5-HAM, Atmos. Chem. Phys., 10, 10733-10752, doi:10.5194/acp-1010733-2010, 2010.

Keskinen, H., Virtanen, A., Joutsensaari, J., Tsagkogeorgas, G., Duplissy, J., Schobesberger, S., Gysel, M., Riccobono, F., Slowik, J. G., Bianchi, F., Yli-Juuti, T., Lehtipalo, K., Rondo, L., Breitenlechner, M., Kupc, A., Almeida, J., Amorim, A., Dunne, E. M., Downard, A. J., Ehrhart, S., Franchin, A., Kajos, M. K., Kirkby, J., Kürten, A., Nieminen, T., Makhmutov, V., Mathot, S., Miettinen, P., Onnela, A., Petäjä, T., Praplan, A., Santos, F. D., Schallhart, S., Sipilä, M., Stozhkov, Y., Tomé, A., Vaattovaara, P., Wimmer, D., Prevot, A., Dommen, J., Donahue, N. M., Flagan, R.C., Weingartner, E., Viisanen, Y., Riipinen, I., Hansel, A., Curtius, J., Kulmala, M., Worsnop, D. R., Baltensperger, U., Wex, H., Stratmann, F., and Laaksonen, A.: Evolution of particle composition in CLOUD nucleation experiments, Atmos. Chem. Phys., 13, 5587-5600, doi:10.5194/acp-13-5587-2013, 2013.

Kirkby, J., Curtius, J., Almeida, J. o., Dunne, E., Duplissy, J., Ehrhart, S., Franchin, A., Gagné, S., Ickes, L., Kürten, A., Kupc, A., Metzger, A., Riccobono, F., Rondo, L., Schobesberger, S., Tsagkogeorgas, G., Wimmer, D., Amorim, A., Bianchi, F., Breitenlechner, M., David, A., Dommen, J., Downard, A., Ehn, M., Flagan, R. C., Haider, S., Hansel, A., Hauser, D., Jud, W., Junninen, H., Kreissl, F., Kvashin, A., Laaksonen, A., Lehtipalo, K., Lima, J., Lovejoy, E. R., Makhmutov, V., Mathot, S., Mikkilä, J., Minginette, P., Mogo, S., Nieminen, T., Onnela, A., Pereira, P., Petäjä, T., Schnitzhofer, R., Seinfeld, J. H., Sipilä, M., Stozhkov, Y., Stratmann, F., Tomé, A., Vanhanen, J., Viisanen, Y., Vrtala, A., Wagner, P. E., Walther, H., Weingartner, E., Wex, H., Winkler, P. M., Carslaw, K. S., Worsnop, D. R., Baltensperger, U., and Kulmala, M.: Role of sulphuric acid, ammonia and galactic cosmic rays in atmospheric aerosol nucleation, Nature, 476, 429-433, doi:10.1038/nature10343, 2011.

Kontkanen, J., Lehtinen, K. E. J., Nieminen, T., Manninen, H. E., Lehtipalo, K., Kerminen, V.-M., and Kulmala, M.: Estimating the contribution of ion-ion recombination to sub- $2 \mathrm{~nm}$ cluster concentrations from atmospheric measurements, Atmos. Chem. Phys., 13, 11391-11401, doi:10.5194/acp-13-11391-2013, 2013.
Ku, B. K. and de la Mora, J. F.: Relation between Electrical Mobility, Mass, and Size for Nanodrops 1-6.5 nm in Diameter in Air, Aerosol Sci. Tech., 43, 241-249, doi:10.1080/02786820802590510, 2009.

Kulmala, M., Maso, M. D., Mäkelä, J. M., Pirjola, L., Väkevä, M., Aalto, P., Miikkulainen, P., Hämeri, K., and O'Dowd, C. D.: On the formation, growth and composition of nucleation mode particles, Tellus B, 53, 479-490, doi:10.1034/j.16000889.2001.530411.x, 2001.

Kulmala, M., Kontkanen, J., Junninen, H., Lehtipalo, K., Manninen, H. E., Nieminen, T., Petaja, T., Sipila, M., Schobesberger, S., Rantala, P., Franchin, A., Jokinen, T., Jarvinen, E., Aijala, M., Kangasluoma, J., Hakala, J., Aalto, P. P., Paasonen, P., Mikkila, J., Vanhanen, J., Aalto, J., Hakola, H., Makkonen, U., Ruuskanen, T., Mauldin, R. L., Duplissy, J., Vehkämäki, H., Back, J., Kortelainen, A., Riipinen, I., Kurten, T., Johnston, M. V., Smith, J. N., Ehn, M., Mentel, T. F., Lehtinen, K. E. J., Laaksonen, A., Kerminen, V.-M., and Worsnop, D. R.: Direct Observations of Atmospheric Aerosol Nucleation, Science, 339, 943946, doi:10.1126/science.1227385, 2013.

Kupc, A., Amorim, A., Curtius, J., Danielczok, A., Duplissy, J., Ehrhart, S., Walther, H., Ickes, L., Kirkby, J., Kürten, A., Lima, J., Mathot, S., Minginette, P., Onnela, A., Rondo, L., and Wagner, P.: A fibre-optic UV system for $\mathrm{H}_{2} \mathrm{SO}_{4}$ production in aerosol chambers causing minimal thermal effects, J. Aerosol Sci., 42, 532-543, doi:10.1016/j.jaerosci.2011.05.001, 2011.

Kurtén, T., Noppel, M., Vehkamäki, H., Salonen, M., and M., Kulmala: Quantum chemical studies of hydrate formation of $\mathrm{H}_{2} \mathrm{SO}_{4}$ and $\mathrm{HSO}_{4-}^{-}$, Boreal. Environ. Res., 12, 431-453, 2007.

Laakso, L., Petäjä, T., Lehtinen, K. E. J., Kulmala, M., Paatero, J., Laakso, L., Petäjä, T., Lehtinen, K. E. J., Kulmala, M., Paatero, J., Hõrrak, U., Tammet, H., and Joutsensaari, J.: Ion production rate in a boreal forest based on ion, particle and radiation measurements, Atmos. Chem. Phys., 4, 1933-1943, doi:10.5194/acp4-1933-2004, 2004.

Leblanc, F., Aplin, K., Yair, Y., Harrison, G., Lebreton, J. P., and Blanc, M.: Planetary Atmospheric Electricity, edited by: Leblanc, F., Aplin, K., Yair, Y., Harrison, G., Lebreton, J. P., and Blanc, M., Springer Science \& Business Media, 30, 532 pp., 2008.

Lee, H. S. and Johnsen, R.: Ion-ion recombination studies in ambient helium and argon at atmospheric densities, J. Chem. Phys., 90, 6328-6334, doi:10.1063/1.456349, 1989.

Leppä, J., Anttila, T., Kerminen, V.-M., Kulmala, M., and Lehtinen, K. E. J.: Atmospheric new particle formation: real and apparent growth of neutral and charged particles, Atmos. Chem. Phys., 11, 4939-4955, doi:10.5194/acp-11-4939-2011, 2011.

Loeb, L. B.: Basic Processes of Gaseous Electronics, University of California Press, Berkeley, 01149, 1955.

López-Yglesias, X. and Flagan, R. C.: Ion-Aerosol Flux Coefficients and the Steady-State Charge Distribution of Aerosols in a Bipolar Ion Environment, Aerosol Sci. Tech., 47, 688-704, doi:10.1080/02786826.2013.783684, 2013.

Luts, A.: Temperature variation of the evolution of positive small air ions at constant relative humidity, J. Atmos. Sol.-Terr. Phy., 60, 1739-1750, doi:10.1016/S1364-6826(98)00151-5, 1998.

Luts, A. and Salm, J.: Chemical composition of small atmospheric ions near the ground, J. Geophys. Res.-Atmos., 99, 1078110785, doi:10.1029/93JD03225, 1994. 
Luts, A., Parts, T., Hõrrak, U., Junninen, H., and Kulmala, M.: Composition of negative air ions as a function of ion age and selected trace gases: Mass- and mobility distribution, J. Aerosol Sci., 42, 820-838, doi:10.1016/j.jaerosci.2011.07.007, 2011.

Mäkelä, J. M., Riihelä, M., Ukkonen, A., Jokinen, V., and Keskinen, J.: Comparison of mobility equivalent diameter with KelvinThomson diameter using ion mobility data, J. Chem. Phys., 105, 1562-1571, doi:10.1063/1.472017, 1996.

Manninen, H. E., Petäjä, T., Asmi, E., Riipinen, I., Nieminen, T., Mikkilä, J., Hõrrak, U., Mirme, A., Mirme, S., Laakso, L., Kerminen, V.-M., and Kulmala, M.: Long-term field measurements of charged and neutral clusters using Neutral cluster and Air Ion Spectrometer (NAIS), Boreal Environ. Res., 14, 591-605, 2009.

Manninen, H. E., Nieminen, T., Asmi, E., Gagné, S., Häkkinen, S., Lehtipalo, K., Aalto, P., Vana, M., Mirme, A., Mirme, S., Hõrrak, U., Plass-Dülmer, C., Stange, G., Kiss, G., Hoffer, A., Törö, N., Moerman, M., Henzing, B., de Leeuw, G., Brinkenberg, M., Kouvarakis, G. N., Bougiatioti, A., Mihalopoulos, N., O’Dowd, C., Ceburnis, D., Arneth, A., Svenningsson, B., Swietlicki, E., Tarozzi, L., Decesari, S., Facchini, M. C., Birmili, W., Sonntag, A., Wiedensohler, A., Boulon, J., Sellegri, K., Laj, P., Gysel, M., Bukowiecki, N., Weingartner, E., Wehrle, G., Laaksonen, A., Hamed, A., Joutsensaari, J., Petäjä, T., Kerminen, V.-M., and Kulmala, M.: EUCAARI ion spectrometer measurements at 12 European sites - analysis of new particle formation events, Atmos. Chem. Phys., 10, 7907-7927, doi:10.5194/acp-10-79072010, 2010.

Manninen, H. E., Franchin, A., Schobesberger, S., Hirsikko, A., Hakala, J., Skromulis, A., Kangasluoma, J., Ehn, M., Junninen, H., Mirme, A., Mirme, S., Sipilä, M., Petäjä, T., Worsnop, D. R., and Kulmala, M.: Characterisation of corona-generated ions used in a Neutral cluster and Air Ion Spectrometer (NAIS), Atmos. Meas. Tech., 4, 2767-2776, doi:10.5194/amt-4-2767-2011, 2011.

Mayya, Y. S. and Sapra, B. K.: Image forces on a collection of charged particles near conducting surfaces, J. Aerosol Sci., 33, 817-828, doi:10.1016/S0021-8502(02)00038-1, 2002.

McGowan, S.: Ion-Ion Recombination in Laboratory Air, Phys. Med. Biol, 10, 25-40, doi:10.1088/0031-9155/10/1/303, 1965.

McMurry, P. H. and Rader, D. J.: Aerosol Wall Losses in Electrically Charged Chambers, Aerosol Sci. Tech., 4, 249-268, doi:10.1080/02786828508959054, 1985.

Mirme, S. and Mirme, A.: The mathematical principles and design of the NAIS - a spectrometer for the measurement of cluster ion and nanometer aerosol size distributions, Atmos. Meas. Tech., 6, 1061-1071, doi:10.5194/amt-6-1061-2013, 2013.

Mizin, S. V., Makhmutov, V. S., Maksumov, O. S., and Kvashnin, A. N.: Application of multithreading programming to physical experiment, Bulletin of the Lebedev Physics Institute, 38, 34-40, doi:10.3103/S1068335611020023, 2011.

Nagato, K. and Nakauchi, M.: Experimental study of particle formation by ion-ion recombination, J. Chem. Phys., 141, 164309, doi:10.1063/1.4898376, 2014.

Natanson, G. L.: On the theory of the charging of a microscopic aerosol particles as a result of capture of gas ions, Zhurnal Tekhnicheskoi Fiziki (Transl.), 30, 573-588, 1960.

Ogawa, T.: Fair-weather electricity, J. Geophys. Res.-Atmos., 90, 5951-5960, doi:10.1029/JD090iD04p05951, 1985.
Olenius, T., Kurtén, T., Kupiainen-Määttä, O., Henschel, H., Ortega, I. K., and Vehkamäki, H.: Effect of Hydration and Base Contaminants on Sulfuric Acid Diffusion Measurement: A Computational Study, Aerosol Sci. Tech., 48, 593-603, doi:10.1080/02786826.2014.903556, 2014.

Onasch, T. B., Siefert, R. L., Brooks, S. D., Prenni, A. J., Murray, B., Wilson, M. A., and Tolbert, M. A.: Infrared spectroscopic study of the deliquescence and efflorescence of ammonium sulfate aerosol as a function of temperature, J. Geophys. Res.-Atmos., 104, 21317-21326, doi:10.1029/1999JD900384, 1999.

Schnitzhofer, R., Metzger, A., Breitenlechner, M., Jud, W., Heinritzi, M., De Menezes, L.-P., Duplissy, J., Guida, R., Haider, S., Kirkby, J., Mathot, S., Minginette, P., Onnela, A., Walther, H., Wasem, A., Hansel, A., and the CLOUD Team: Characterisation of organic contaminants in the CLOUD chamber at CERN, Atmos. Meas. Tech., 7, 2159-2168, doi:10.5194/amt-7-2159-2014, 2014.

Smirnov, I.: Modeling of ionization produced by fast charged particles in gases, Nuclear Instruments and Methods in Physics Research Section A: Accelerators, Spectrometers, Detectors and Associated Equipment, 554, 474-493, doi:10.1016/j.nima.2005.08.064, 2005.

Smith, D. and Adams, N. G.: Ionic recombination in the stratosphere, Geophys. Res. Lett., 9, 1085-1087, doi:10.1029/GL009i009p01085, 1982.

Smith, D. and Spanel, P.: Ions in the terrestrial atmosphere and in interstellar clouds, Mass Spectrom. Rev., 14, 255-278, doi:10.1002/mas.1280140403, 1995.

Tammet, H. and Kulmala, M.: Simulation tool for atmospheric aerosol nucleation bursts, J. Aerosol Sci., 36, 173-196, doi:10.1016/j.jaerosci.2004.08.004, 2005.

Tammet, H., Hõrrak, U., Laakso, L., and Kulmala, M.: Factors of air ion balance in a coniferous forest according to measurements in Hyytiälä, Finland, Atmos. Chem. Phys., 6, 3377-3390, doi:10.5194/acp-6-3377-2006, 2006.

Thomson, J.: XXIX. Recombination of gaseous ions, the chemical combination of gases, and monomolecular reactions, Phil. Mag. Ser., 6, 337-378, doi:10.1080/14786442408634372, 1924.

Thomson, J. J. and Thomson, G. P.: Conduction of Electricity Through Gases: Volume 1, Ionisation by Heat and Light, Cambridge University Press, England, 2013.

Tinsley, B. A.: Influence of solar wind on the global electric circuit, and inferred effects on cloud microphysics, temperature, temperature, and dynamics in the troposphere, Space Sci. Rev., 94, 231$258,2000$.

Usoskin, I. G. and Kovaltsov, G. A.: Cosmic rays and climate of the Earth: Possible connection, C. R. Geosci., 340, 441-450, 2008.

Usoskin, I. G., Gladysheva, O. G., and Kovaltsov, G. A.: Cosmic ray-induced ionization in the atmosphere: spatial and temporal changes, J. Atmos. Sol.-Terr. Phy., 66, 1791-1796, 2004.

Vauge, C.: On the concept of "image-force", J. Aerosol Sci., 33, 829-832, doi:10.1016/S0021-8502(02)00037-X, 2002.

Voigtländer, J., Duplissy, J., Rondo, L., Kürten, A., and Stratmann, F.: Numerical simulations of mixing conditions and aerosol dynamics in the CERN CLOUD chamber, Atmos. Chem. Phys., 12, 2205-2214, doi:10.5194/acp-12-2205-2012, 2012.

Volland, H.: Handbook of Atmospheric Electrodynamics, CRC Press, Boca Raton, FL, 1, 1995 
Williams, A. G., Zahorowski, W., Chambers, S., Griffiths, A., Hacker, J. M., Element, A., and Werczynski, S.: The Vertical Distribution of Radon in Clear and Cloudy Daytime Terrestrial Boundary Layers, J. Atmos. Sci., 68, 155-174, doi:10.1175/2010JAS3576.1, 2011.

Yu, F.: Ion-mediated nucleation in the atmosphere: Key controlling parameters, implications, and look-up table, J. Geophys. Res.Atmos., 115, D03206, doi:10.1029/2009JD012630, 2010.

Yu, F. and Turco, R.: Case studies of particle formation events observed in boreal forests: implications for nucleation mechanisms, Atmos. Chem. Phys., 8, 6085-6102, doi:10.5194/acp-86085-2008, 2008.
Yu, F., Luo, G., Bates, T. S., Anderson, B., Clarke, A., Kapustin, V., Yantosca, R. M., Wang, Y., and Wu, S.: Spatial distributions of particle number concentrations in the global atmosphere: Simulations, observations, and implications for nucleation mechanisms, J. Geophys. Res., 115, D17205, doi:10.1029/2009JD013473, 2010.

Zhang, K., Feichter, J., Kazil, J., Wan, H., Zhuo, W., Griffiths, A. D., Sartorius, H., Zahorowski, W., Ramonet, M., Schmidt, M., Yver, C., Neubert, R. E. M., and Brunke, E.-G.: Radon activity in the lower troposphere and its impact on ionization rate: a global estimate using different radon emissions, Atmos. Chem. Phys., 11, 7817-7838, doi:10.5194/acp-11-7817-2011, 2011. 